\title{
Adherence to Antihypertensive Treatment and Associated Factors
}

\author{
NICOLÁS F. RENNA, MD PHD ISHF \\ Lead Hypertension Unit. Hospital Español de Mendoza, Collage of Medice. \\ UNCuyo-CONICET-Argentina.
}

DOI:10.30824/2110-14

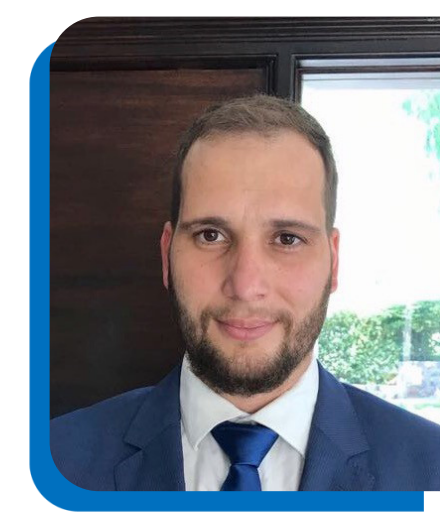

High blood pressure is one of the most important risk factors for ischemic heart disease, stroke, chronic kidney disease, and dementia. The prevalence of hypertension has decreased substantially in high-income regions. In contrast, blood pressure has risen in low- and middleincome countries. The use and efficacy of hypertension treatment vary substantially between countries. Factors influencing this variance include a country's financial resources, the extent of health insurance and health infrastructure, the frequency with which people interact with doctors and non-medical health personnel, and the availability of medicines. ${ }^{(1)}$

One of the fundamental pillars to achieve adequate blood pressure control is adherence. Adherence to hypertension treatment 1 year after onset is near to $50 \%$. $(2,3)$. The adherence was defined as the extent to which a person's behaviour when taking medications, following a diet, and making lifestyle changes is consistent with the agreed-upon recommendations of a healthcare provider. ${ }^{(4)}$

Adherence is a process characterized by 3 components: initiation, implementation, and discontinuation. In clinical practice, non-initiation reaches reach to $>$ $20 \%$ in hypertension treated patients; however, this phenomenon can vary considerably according to the countries and access to medications. When the next dose is omitted to be taken and then treatment is stopped, this marks the interruption of the treatment. This parameter allows the definition of persistence, which is the period between the start and the last dose immediately before to interruption. Non-persistence is one of the most frequent causes of poor adherence in hypertension, with $50 \%$ of patients having interrupted treatment one year after starting treatment. ${ }^{(5)}$

But how can we detect non-adherence to antihypertensive treatment? The ideal method for assessing drug adherence should provide reliable capture, storage, analysis, and communication of dosing history data in a way that makes it difficult or impossible for patients or trial staff to censor or manipulate the data. To date, none of the available systems meets all these criteria.

A method that has gradually been acquiring more evidence, the electronic monitoring system for medication adherence, known as the Medication Event Monitoring System (MEMS), but its implementation in clinical practice is still limited to expert centres. This system is analogous to the determination of drug levels where the total absence of a compound is more relevant in terms of non-adherence than the actual presence of the drug ( $97 \%$ accurate). Besides, electronic monitoring systems provide information on drug use behaviours (taking, time, frequency of omissions, compensatory intakes) based on dosing history. ${ }^{(6)}$

The selection of prescribed drugs to antihypertensive treatment has an impact on adherence and persistence essentially due to the side effect profile, the number of drugs taken and patient confidence. A fixed dose combination that includes two or more active pharmaceuticals combined in a single pill combination (SPC) could be a strategy for overcoming no adherence. The initial choice of antihypertensive drugs it is very important because could affect the patient's first therapeutic experience and the doctor's decisions in daily practice. ${ }^{(7)}$

SPC is an appropriate therapeutic option and can be implemented in most low-income countries because it is a cost-effective strategy. It also produces a rapid and sustained decrease in BP, since hypertension is a multifactorial disease, the combination of drug classes increases the antihypertensive effect, improving the control rate, also conferring greater cardiovascular prevention. A similar concept is the polypill, which provides this, in addition to adequate blood pressure control, cardiovascular protection because it combines 
antihypertensive, lipid-lowering and, although not always, aspirin. ${ }^{(8)}$

\section{References}

1. Zhou, B., Perel, P., Mensah, G.A. et al. Global epidemiology, health burden and effective interventions for elevated blood pressure and hypertension. Nat Rev Cardiol (2021).

2. Vrijens B, Vincze G, Kristanto P, Urquhart J, Burnier M. Adherence to prescribed antihypertensive drug treatments: longitudinal study of electronically compiled dosing histories.BMJ. 2008; 336:1114-1117. doi: 10.1136/ bmj.39553.670231.25

3. Hill MN, Miller NH, Degeest S, Materson BJ, Black HR, Izzo JL, Oparil S, Weber MA; American Society of Hypertension Writing Group. Adherence and persistence with taking medication to control high blood pressure.J Am Soc Hypertens. 2011; 5:56-63. doi: 10.1016/j. jash.2011.01.001

4. Adherence to Long-term Therapies Evidence for Action. Bulletin World Health Organization (WHO) 2003, 216 pages
5. Vrijens B, De Geest S, Hughes DA, Przemyslaw K, Demonceau J, Ruppar T, Dobbels F, Fargher E, Morrison V, Lewek P, Matyjaszczyk M, Mshelia C, Clyne W, Aronson JK, Urquhart J; ABC Project Team. A new taxonomy for describing and defining adherence to medications. Br J Clin Pharmacol. 2012; 73:691-705. doi: 10.1111/j.1365-2125.2012.04167.x

6. Burnier M, Egan BM. Adherence in Hypertension. Circ Res. 2019 Mar 29;124(7):1124-1140

7. Position Statement on Use of Pharmacological Combinations in a Single Pill for Treatment of Hypertension by Argentine Federation of Cardiology (FAC) and Argentine Society of Hypertension (SAHA). Renna NF, Piskorz D, Stisman D, Martinez D, Lescano L, Vissani S, Espeche W, Marquez D, Parodi D, Naninni D, Baroni M, Llanos D, Martinez R, Barochinner J, Staffieri G, Lanas F, Velásquez M, Marin M, Williams B, Ennis I. J Human Hyper 2021doi: 10.1038/s41371-021-00557-w

8. Muñoz D, Uzoije P, Reynolds C, Miller R, Walkley D, Pappalardo S, Tousey P, Munro H, Gonzales H, Song W, White C, Blot WJ, Wang TJ. Polypill for Cardiovascular Disease Prevention in an Underserved Population. N Engl J Med. 2019 Sep 19;381(12):1114-1123.

\title{
NEW BLOOD \\ Cardiorenal Syndrome: immune system as an intriguing connector between Heart and Kidney
}

\author{
CAROLINA VICTORIA CRUZ JUNHO \& MARCELA SORELLI CARNEI- \\ RO-RAMOS \\ Laboratory of Cardiovascular Immunology. Center of Natural and Human \\ Sciences (CCNH). Federal University of ABC. Santo André. SP. Brazil.
}

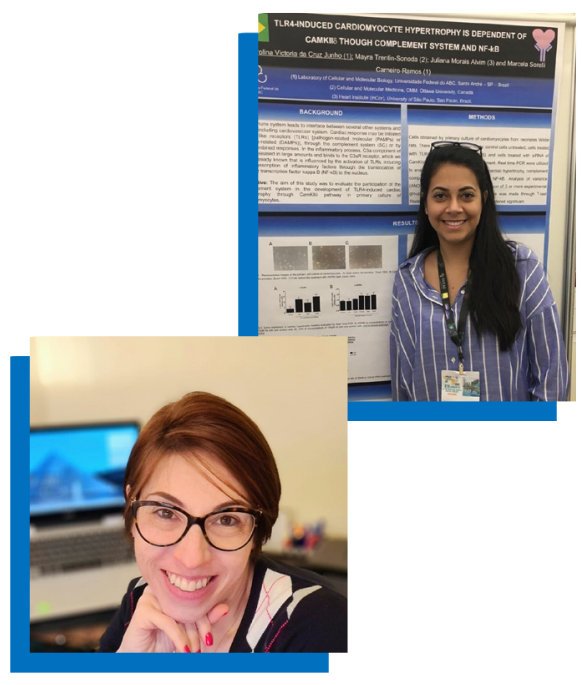

DOI:10.30824/2106-15

Since 1836 when Robert Bright first described the relationship between heart and kidneys, the scientific community has dedicated itself to better understanding the mechanisms involved in the kidney-heart axis, known in recent decades as cardiorenal syndrome (CRS) ${ }^{[1]}$. CRS can be classified into 5 different types, where types 1 and 2 are defined by acute or chronic cardiac alterations that lead to renal dysfunction, types 3 and 4 defined by acute or chronic renal alterations responsible for later cardiac alterations, and finally type 5 , characterized by concomitant dysfunctions of the kidneys and heart due to systemic alterations such as 